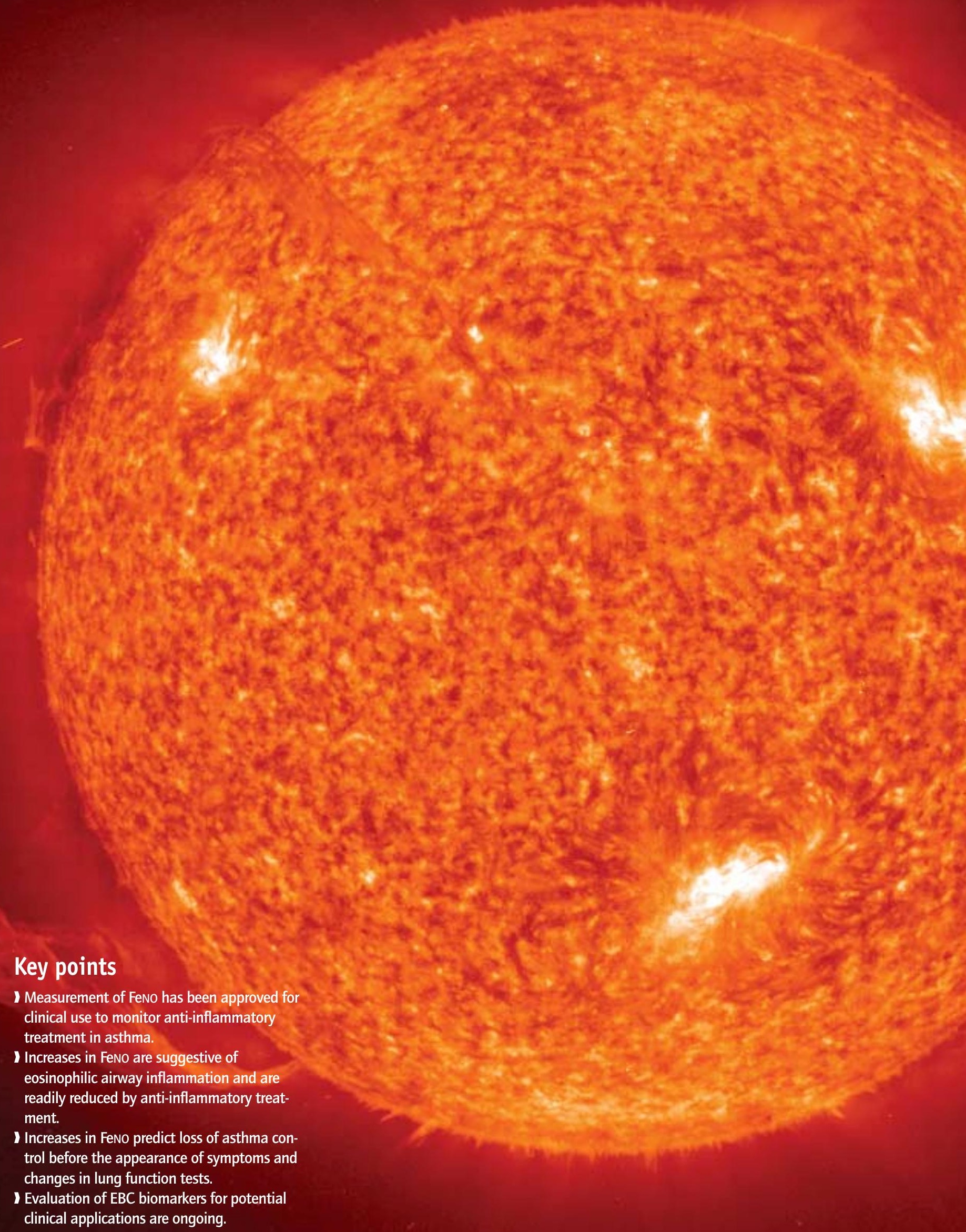




\section{Airway inflammation: exhaled NO measurement in clinical practice}

\section{Educational aims}

Long term: to improve management of asthma and other chronic inflammatory airway diseases.

I Short term: to introduce the measurement of exhaled NO; to summarise the main points of current guidelines for exhaled NO measurement; to give information on the usefulness of exhaled NO measurement in asthma management; and to give basic information on exhaled breath condensate.

\section{Summary}

Asthma is defined as an inflammatory disorder of the airways. Therefore, it is reasonable to add an "inflammometer" to the available methods of disease monitoring. In this respect, several biomarkers have been tested from different samples, including blood, urine and exhaled breath. Breath tests for the determination of exhaled biomarkers offer great opportunities for disease monitoring, as they are simple, completely non-invasive, can be performed in children and also in severe patients, and can be repeated even at short intervals. This article will focus on the use of exhaled biomarkers to monitor airway inflammation. The central aim is to introduce the measurement of exhaled NO as a prototype for the application of biomarkers in the management of asthma. The field of EBC is also mentioned to give some background information on the sampling of non-volatile biomarkers in exhaled breath.

Airway inflammation is centrally important in asthma and other lung diseases. Currently, asthma is viewed as a chronic inflammatory airway disease, and international guidelines place great importance on treating inflammation in this condition [1]. In contrast, the assessment of disease severity and progression is based on clinical symptoms and lung function tests. Monitoring of inflammation is not included in current asthma guidelines, although it has been demonstrated that monitoring the nature, extent and intensity of inflammation improves asthma control [2].

\section{What can serve as an "inflammometer"?}

Methods used in everyday clinical practice are not suitable for the assessment of airway inflammation. Symptoms and their perceptions vary widely between individuals and do not accurately reflect the extent of airway inflammation. Lung function measurements are used to monitor disease activity; however, it has been recognised that changes in lung function tests are not closely related to the degree of inflammation, and intensive inflammatory processes
I. Horvath

Correspondence:
I. Horvath
National Koranyi Institute for
Pulmonology
Dept of Pathophysiology
Budapest
Piheno u. 1
H-1529
Hungary
Fax: 36 13943521
E-mail: hildiko@koranyi.hu


may well precede changes in lung function $[3,4]$. Conversely, direct assessment of airway inflammation using bronchoscopy cannot be used for monitoring due to its invasive nature. Sputum induction is another way of obtaining cells from the lower airways and it has been demonstrated that its use improves asthma control $[2,5]$. This sampling method, however, requires inhalation of a hypertonic salt solution, which may provoke bronchoconstriction in asthmatic patients. Furthermore, processing the sputum samples requires $\sim 2$ hours work by a well-trained person to obtain reliable readings, and, at the moment, these features limit its wide clinical use. Along these lines, the least invasive technique is the collection of exhaled breath samples. Several mediators are present in the exhaled breath and are shown in table 1, although the list does not contain all of the determined molecules in exhaled breath condensate (EBC) [6]. Some of them, including nitric oxide (NO) and carbon monoxide (CO), can be measured in the gas phase, while others, such as hydrogen peroxide,

\section{Table 1 Mediators demonstrated in exhaled breath and proposed as potential biomarkers}

\section{Exhaled gases}

NO

CO

Ethane

Penthane

Volatile hydrocarbons

Volatile organic compounds
Mediators in the exhaled breath condensate

Adenosine

Ammonia

Hydrogen peroxide

Interleukins $(1,4,6,8)$, interferon- $\gamma$

Endothelin-1

pH

8-Isoprostane

Aldehydes

Nitrite, nitrate, nitrosothiols, nitrotyrosine

Leukotrienes, prostaglandins

Glutathione

Other proposed biomarker: exhaled breath temperature (to reflect bronchial blood flow)

Table 2 Most important points from the guidelines for exhaled NO measurement

$>$ Feno, expressed in ppb, should be used to establish exhaled N0; the exhalation flow rate can be expressed as a subscript of the flow rate in $L \cdot$ second $^{-1}$, e.g. FeN00.05

$>$ Ambient NO should be recorded and NO-free gas ( $<5 p p b)$ should be used for inhalation

> Constant expiratory flow rates should be used and recorded at each measurement: recommended flow rate $=0.05 \mathrm{~L} \cdot$ second $^{-1}$

$>$ Breath hold is not recommended

$>$ NO analysis should be performed before spirometry

> Subjects should refrain from eating, drinking and smoking for 1 hour before measurements

> Serial measurements should be performed at the same time of day and the time recorded

> The following factors should be recorded: age/sex, time of last bronchodilator, food/drinks, time of measurement, smoke exposure, any infections (including HIV) and all current medication adenosine, interleukins and $\mathrm{pH}$, can be determined in the EBC.

\section{Exhaled NO}

It was hardly more than a decade ago when Gustaffson et al. [7] described the presence of NO in exhaled breath. Soon after, two independent groups observed that the concentration of exhaled NO is elevated in asthma [8,9]. These discoveries have been followed by more than 2,000 publications on the measurement of exhaled $\mathrm{NO}$, paving the way for this measurement to enter clinical practice for monitoring the effect of antiinflammatory treatment in asthma [10].

NO is derived from L-arginine by NO synthase (NOS) enzymes, of which there are at least three distinct isoforms in the human body [11]. The cellular source of NO in the lower respiratory tract is not completely known. It is accepted that airway epithelial cells and inflammatory cells, mainly eosinophils, produce NO. In asthmatic airway inflammation, inducible (i)NOS is upregulated in several cell types, and this is likely to be the main reason for increases in exhaled NO in the disease, although differences in other isoforms may also play some role $[12,13]$.

\section{Measurement of exhaled NO}

The use of exhaled NO measurement as a clinical tool requires standardised measurement techniques and reference data in all age groups. Therefore, there has been intensive effort to standardise the measurement, and now there are internationally accepted guidelines for exhaled NO measurement both for adults $[14,15]$ and children [16] (table 2). A European Respiratory Society (ERS) Task Force published its recommendations in 1997 [14], and the American Thoracic Society (ATS) published a statement in 1999 [15], which has now been updated and will be published soon. A statement on paediatric exhaled NO measurement approved by the ATS and ERS is also available [16].

The recommendations have detailed instructions for offline NO recordings, recordings under special circumstanses (i.e. infants, ventilated patients), multiple flow measurements and technical requirements for $\mathrm{NO}$ analysers. Furthermore, they also contain details for the measurement of nasal NO and its suggested application for the differential diagnosis of primary ciliary dyskinesia (PCD). 


\section{Equipment for direct exhaled and nasal NO measurement}

There are several commercially available analysers for exhaled and nasal NO measurements: LR2000 analyser (Logan Research Ltd, Rochester, UK), NIOX ${ }^{\circledR}$ NO analyser (Aerocrine, Solna, Sweden; figure 1), Sievers ${ }^{\circledR}$ (Ionics Instrument, Boulder, CO, USA), and ECO Physics NO analyser (ECOPHYSICS, Durnten, Switzerland). The NIOX ${ }^{\circledR}$ NO analyser has been approved for medical use in the European Union and was also cleared by the US Food and Drug Administration for clinical application in patients with asthma in 2003 [10].

In addition, the feasibility of measuring NO in clinical practice is improving. For example, the development of portable, lightweight NO analysers that can be used in the home has important consequences for the self-management of asthma in the future.

\section{How to perform online NO measurement}

When performing online NO measurement, the patient should be seated comfortably, with the mouthpiece at the proper height and position. A nose clip should not be used. The patient inserts a mouthpiece and inhales for 2-3 seconds through the mouth to total lung capacity (TLC), or near TLC if it is difficult to achieve, and then exhales immediately against a mouthpiece pressure $\left(5-20 \mathrm{cmH}_{2} \mathrm{O}\right)$, to ensure velum closure to exclude contamination from nasal NO, with a recommended expiratory flow rate of $0.05 \mathrm{~L} \cdot \mathrm{sec}-$ ond $^{-1}$ (BTPS). Approximately 10 seconds are required to obtain a stable NO plateau.

\section{How to interpret FenO recordings}

Peaks at the beginning of exhalation are ignored (they may represent NO from ambient air or from oropharyngeal sources), and only NO plateaus are interpreted. A plateau can be accepted if it is held for $\geq 3$ seconds and does not drift $>10 \%$ over this 3-second time frame. Measurements should be repeated to obtain at least two NO plateau values that agree within $10 \%$ of each other.

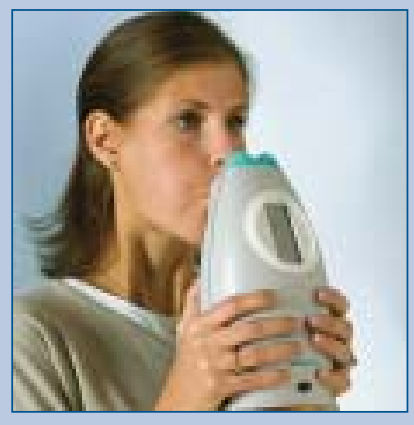

Figure 1

Measurement of exhaled NO.
Exhaled NO is calculated as the mean of two values (figure 2).

\section{How to interpret FenO concentrations}

In non-smokers, fractional exhaled NO concentration $\left(\mathrm{FeNO}_{50}\right.$ ) between $5-20 \mathrm{ppb}$ can be considered normal. Values $>20$ ppb are considered as elevated. Elevated Feno is seen in asthma, but other conditions, including viral infection of the airways, bronchiolitis obliterans syndrome and chronic obstructive pulmonary disease (COPD), may also be associated with moderately increased concentrations of exhaled NO [6]. In asthmatic patients, values can increase up to 3-5-fold when compared with normal values. Markedly increased Feno values are indicative of eosinophilic airway inflammation and predict a good response to steroid treatment. Values $<5$ ppb are seen in cystic fibrosis (CF) and in patients with PCD.

Figure 2

NO chart.

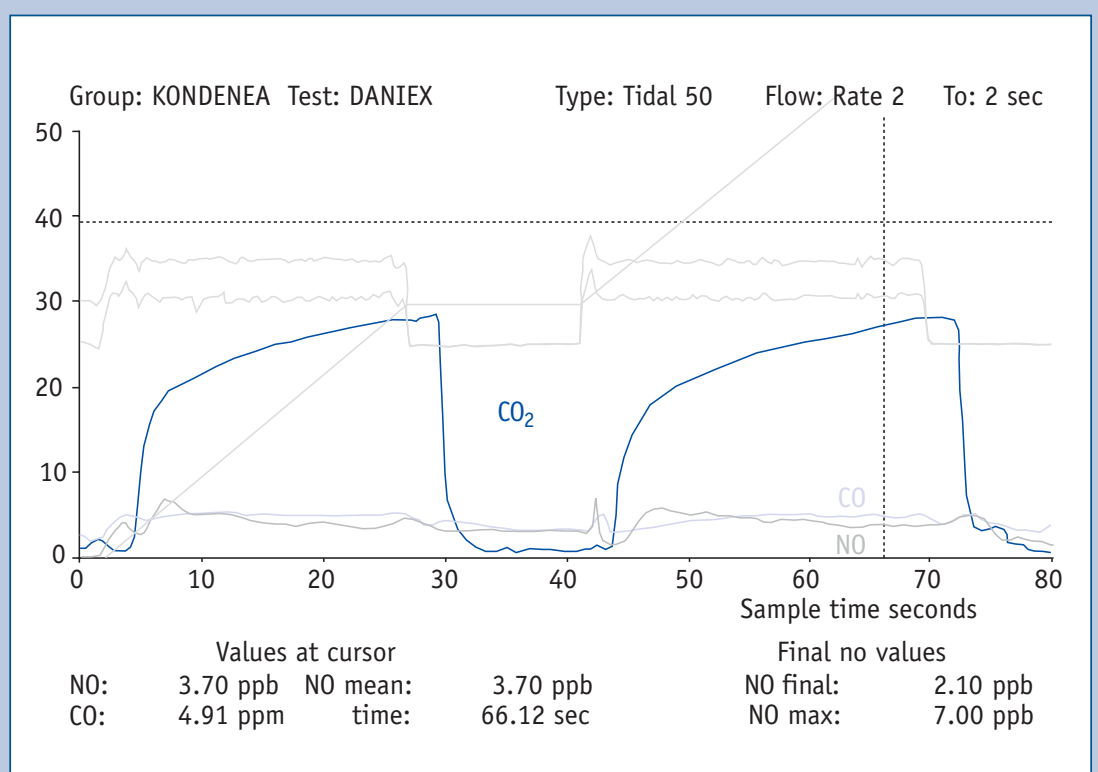




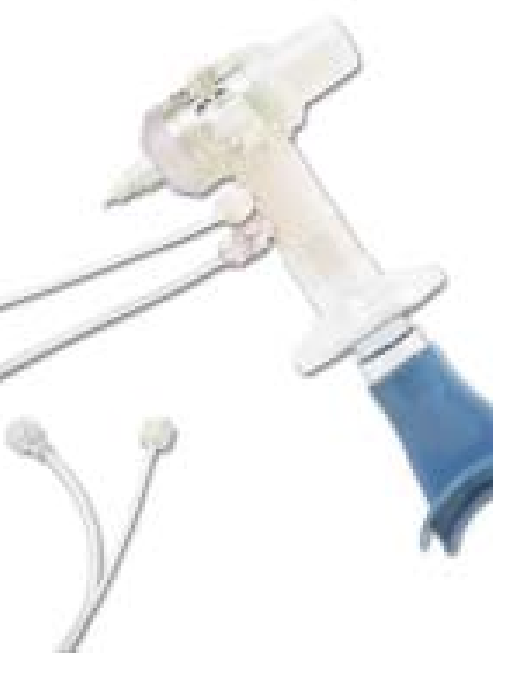

Figure 3

Major airway diseases are associated with different values of exhaled NO, with some overlap between them.

\section{Exhaled NO in asthma management}

To date, Feno has only been cleared for monitoring the effect of anti-inflammatory medication in patients with asthma, although there are several other potential applications of this measurement, i.e. monitoring of lung transplant recipients.

\section{Early diagnosis of asthma}

The level of exhaled NO is elevated in atopic subjects with increased airway hyperresponsiveness, where subclinical airway inflammation is likely to be already present [17]. Elevation of exhaled NO can be found in approximately one-third of patients with allergic rhinitis, which may indicate ongoing inflammatory changes in the lower airways [18]. Furthermore, adolescents with a history of childhood asthma have increased exhaled NO levels without having asthma symptoms [4]. Recent studies have demonstrated that exhaled NO is superior to conventional tests, including baseline respiratory function and bronchodilator responsiveness, in identifying patients with probable asthma, both in children and adults [19,20].

\section{Differential diagnosis}

In asthma, levels of exhaled NO can be increased several-fold when compared with healthy subjects $[8,9,21]$; whereas, in other inflammatory diseases of the airways, this elevation (if there is an elevation at all) is a lot less pronounced, although there is an important overlap between different patients [22-24] (figure 3). The exhaled $\mathrm{NO}$ measurement is also useful in the differential diagnosis of patients with dry cough $[25,26]$. It is important to mention, however, that the typical high increase in exhaled NO is mostly seen in atopic asthmatic patients, and some studies have shown that normal levels of exhaled NO can be detected in non-atopic asthmatic subjects [27]. This observation may be explained by the fact

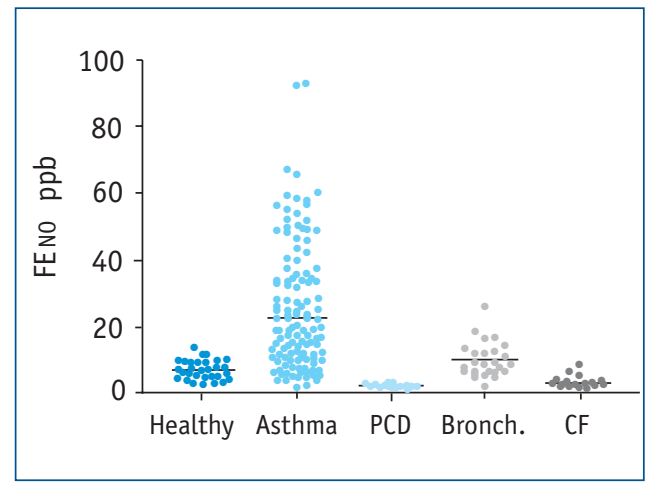

that, in non-atopic asthma, neutrophilic inflammation is sometimes seen instead of the characteristic eosinophilic inflammation observed in atopic asthma [28], and elevation in exhaled NO is closely linked with eosinophil cell count [29] but not with neutrophils.

\section{Other markers of airway inflammation}

Levels of exhaled NO are associated with airway hyperresponsiveness [29-31], number of eosinophil cells in the blood [31] and induced sputum [29, 32, 33], and also with the concentration of eosinophilic cationic protein [34]. The close relationship between eosinophil cell number and exhaled NO levels suggests that exhaled $\mathrm{NO}$ is a marker of eosinophilic inflammation. In asthma exacerbations, and also during the late phase of allergen-induced airway responses, the concentration of exhaled NO increases [35-37]. Furthermore, increases in exhaled NO levels can be observed during natural allergen exposure $[38,39]$, further confirming that changes in exhaled NO level reflect changes in asthmatic airway inflammation.

\section{Monitoring anti-inflammatory treatment}

Inhalation of methacholine or salbutamol does not alter exhaled NO [40, 41], although there is evidence that metacholine challenge does influence NO measurements [42]. Anti-inflammatory treatment, either with corticosteroids or with leukotriene antagonists, causes a decrease in exhaled NO [43-50], proving that elevation in exhaled NO levels in steroid-naïve asthmatics is due to NO overproduction linked with inflammation. Treatment with inhaled and/or oral corticosteroids causes a dose-dependent reduction in exhaled NO $[42,43]$. The reduction in exhaled NO by anti-inflammatory treatment is explained by the suppression of inflammation, resulting in reduced levels of inflammatory cytokines and, therefore, a decrease in the signal for NO overproduction by iNOS. Regarding other drugs used for asthma, theophylline has no effect on exhaled NO levels [51].

Exhaled NO levels are in the normal range or close to it in well-controlled patients with asthma. Longitudinal studies have shown that, in steroidtreated patients with a stable condition, reduction of the dose of steroids causes an increase in exhaled NO level, which precedes the worsening of symptoms, lung function and also the increase in sputum eosinophils $[50,52]$. 
Based on the relationship between changes in clinical measures of asthma control and exhaled NO level, measurement of exhaled NO seems to be a useful marker for monitoring the efficacy of asthma control [52-53]. This suggestion is further confirmed by the findings of others, showing that Feno predicts asthma relapse in asymptomatic asthmatic patients after the withdrawal of corticosteroids [54-57]. A recent study showed that the elevation in Feno predicted loss of asthma control in patients having no symptoms or change in spirometry with a sensitivity of $71 \%$ and a specificity of $93 \%$ if a Feno value of $49 \mathrm{ppb}$ was chosen for cut-off level. This finding has an important clinical implication because elevation of Feno warns the clinician about the worsening of airway inflammation, indicating the need to start on treatment before symptoms appear. Another longitudinal study addressed FenO as a predictor of loss of asthma control related to the withdrawal of steroids in adults [57]. Jones et al. [57] studied exhaled NO weekly for 11 weeks in 78 subjects with asthma who abruptly stopped their inhaled corticosteroids. They found that in subjects who eventually experienced loss of control, exhaled NO levels had increased significantly higher and more rapidly than in those remaining clinically stable. In this study, exhaled NO levels at the visit before loss of control were predictive of the upcoming exacerbation (positive predictive value of $80-90 \%$ ) at a time when symptoms remained stable. However, there is still some controversy whether or not increased NO levels can predict exacerbation of asthma [58].

Smoking causes a decrease in Feno both in healthy subjects and in asthmatic patients, but asthmatic smokers have higher Feno concentrations than healthy smokers, suggesting that the measurement may also be useful for this patient group [59].

\section{How to interpret Feno data}

In asthma, the use of exhaled NO has been proposed to diagnose asthma, to monitor the response to anti-inflammatory therapy, to evaluate compliance and to predict upcoming asthma exacerbations. Furthermore, it is also proposed that adjusting anti-inflammatory medications guided by the monitoring of non-invasive markers, such as sputum eosinophils and exhaled NO, could improve overall asthma control.

Along these lines, elevated Feno values seen in untreated patients confirm the diagnosis of asthma suggestive of ongoing eosinophilic airway inflammation. Successful anti-inflammatory treatment causes a decrease in FeNo, which remains low if the patient is stable. If Feno is not decreased, this may be caused by non-compliance or by insufficient dose of corticosteroids. Low FenO values seen in patients stable on anti-inflammatory treatment increase when airway inflammation worsens, for example, due to allergen exposure.

\section{Biomarkers in EBC}

The measurement of exhaled NO has become part of clinical practice, and the measurement of other biomarkers in exhaled breath are rapidly gaining attention.

The collection of EBC is a simple, non-invasive method for obtaining samples from the airways. $\mathrm{EBC}$ sampling only requires the non-invasive collection of exhaled breath during tidal breathing for 10-20 minutes in a cold trap. The obtained fluid, however, is a complex diluted solution of diverse biomarkers with various chemical stabilities, including a variety of constituents $[6,60]$. Due to the complexity of EBC and the fact that it is a much-diluted sample, there are still several unsolved issues surrounding this sampling method. Proposed biomarkers in EBC include adenosine, ammonia, hydrogen peroxide, ions, isoprostanes, prostaglandins, leukotrienes, nitrogen oxides, pH and cytokines. Concentrations of these mediators are influenced by airway diseases, including asthma, COPD, CF and bronchiectasis, and are modulated by therapeutic intervention. Although there is expectation of this sampling method becoming clinically useful, at the moment, there are still many open issues, many of which are highlighted in the report from the ERS/ATS Task Force "Exhaled Breath Condensate", and none of the biomarkers in EBC have been validated sufficiently for clinical use. It is the very diversity of EBC itself that has prevented it from yet achieving clinical applicability. With only a relatively small number of investigators studying each biomarker, the process of advancing standardised methodologies for each individual biomarker is expected to be slower than that for exhaled NO. However, after such validations are indeed accomplished, EBC measurements may improve clinical practice by providing useful information on those critical aspects of disease that are left completely inaccessible by current means.

\section{Educational questions}

1. Has any biomarker been approved for monitoring anti-inflammatory treatment in asthma?

2. What are the two most important requirements for exhalation when measuring exhaled NO?

3. How would you interpret an $\mathrm{FeNO}_{50}$ of $75 \mathrm{ppb}$ ?

4. What is EBC? 


\section{Suggested further reading}

American Thoracic Society. Recommendations for standardized procedures for the online and offline measurement of exhaled lower respiratory nitric oxide and nasal nitric oxide in adults and children. Am J Respir Crit Care Med 1999; 160: 2104-2117.

Baraldi E, de Jongste JC; European Respiratory Society; American Thoracic Society. Measurement of exhaled nitric oxide in children, 2001. Eur Respir J 2002; 20: 223-237.

Silkoff $P$, Carlson M, Bourke T, Katial R, Ögren E, Szefler SJ. The Aerocrine exhaled nitric oxide monitoring system NIOX is cleared by the US Food and Drug Administration for monitoring therapy in asthma. J Allergy Clin Immunol 2004; 114: 1242-1256.

Horvath I. Exhaled breath condensate in disease monitoring. Clin Pulm Med 2003; 10: 195-200.

\section{References}

1. American Thoracic Society. Standards for the diagnosis and care of patients with chronic obstructive pulmonary disease (COPD) and asthma. Am Rev Respir Dis 1987; 136: 225-244.

2. Green RH, Brightling CE, McKenna S, et al. Asthma exacerbations and sputum eosinophil counts: a randomised controlled trial. Lancet 2002; 360: 1715-1721.

3. Rytila P, Metso T, Heikkinen K, Saarelainen P, Helenius IJ, Haahtela T. Airway inflammation in patients with symptoms suggestive of asthma but with normal lung function. Eur Respir J 2000; 16: 824-830.

4. Toorn LM, Prins J, Overbeek SE, et al. Airway inflammation is present during clinical remission of atopic asthma. Am J Respir Crit Care Med 2001; 164: 2107-2113.

5. Vignola AM, Rennar SI, Hargreave FE, et al. Standardised methodology of sputum induction and processing. Future directions. Eur Respir J 2002; 20: Suppl. 37, 51s-55s.

6. Kharitonov SA, Barnes PJ. Exhaled markers of pulmonary disease. Am J Respir Crit Care Med 2001; 163: $1693-1722$.

7. Gustafsson LE, Leone AM, Persson MG, Wiklund NP, Moncada S. Endogenous nitric oxide is present in the exhaled air of rabbits, guinea pigs and humans. Biochem Biophys Res Commun 1991; 181: 852-857.

8. Alving K, Weitzberg E, Lundberg JM. Increased amount of nitric oxide in exhaled air of asthmatics. Eur Respir J 1993; 6: 1368-1370.

9. Kharitonov SA, Yates D, Robbins RA, Logan-Sinclair R, Shinebourne EA, Barnes PJ. Increased nitric oxide in exhaled air of asthmatics. Lancet 1994; 343: 133-135.

10. Silkoff P, Carlson M, Bourke T, Katial R, Ögren E, Szefler SJ. The Aerocrine exhaled nitric oxide monitoring system NIOX is cleared by the US Food and Drug Administration for monitoring therapy in asthma. J Allergy Clin Immunol 2004; 114: 1242-1256.

11. Stuehr DJ, Griffith OW. Mammalian nitric oxide synthases. Adv Enzymol Relat Areas Mol Biol 1992; 65: $287-346$.

12. Guo FH, Comhair SAA, Zheng S, et al. Molecular mechanism of increased nitric oxide (NO) in asthma: evidence for transcriptional and posttranslational regulation of NO synthesis. J Immunol 2000; 164: 5970-5980.

13. Hansel $\Pi$, Kharitonov SA, Donnelly $L E$, et al. A selective inhibitor of inducible nitric oxide synthase inhibits exhaled breath nitric oxide in healthy volunteers and asthmatics. FASEB J 2003; 17: 1298-1300.

14. Kharitonov SA, Alving K, Barnes PJ. Exhaled and nasal nitric oxide measurements: recommendations. Eur Respir J 1997; 10: 1683-1693.

15. American Thoracic Society. Recommendations for standardized procedures for the online and offline measurement of exhaled lower respiratory nitric oxide and nasal nitric oxide in adults and children. Am J Respir Crit Care Med 1999; 160: 2104-2117.

16. Baraldi E, de Jongste JC; European Respiratory Society; American Thoracic Society. Measurement of exhaled nitric oxide in children, 2001. Eur Respir J 2002; 20: 223-237.

17. Horváth I, Barnes PJ. Exhaled monoxides in asymptomatic atopic subjects. Clin Exp Allergy 1999; 29: 1276-1280.

18. Martin U, Bryden K, Devoy M, Howarth P. Increased level of exhaled nitric oxide during nasal and oral breathing in subjects with seasonal rhinitis. J Allergy Clin Immunol 1996; 97: 768-773.

19. Malmberg LP, Pelkonen AS, Haahtela T, Turpeinen M. Exhaled nitric oxide rather than lung function distinguishes preschool children with probable asthma. Thorax 2003; 58: 494-499.

20. Smith AD, Cowan J0, McLachlan C, Monti-Sheehan, Jackson P. Diagnosing asthma. Comparisons between exhaled nitric oxide measurements and conventional tests. Am J Respir Crit Care Med 2004; 169: 473-478.

21. Persson MG, Zetterstrom 0, Argenius V, Ihre $E$, Gustaffson LE. Single breath nitric oxide measurements in asthmatic patients and smokers. Lancet 1994; 343: 146-147.

22. Horvath I, Loukides S, Wodehouse $T$, et al. Comparison of exhaled and nasal nitric oxide and exhaled carbon monoxide levels in bronchiectatic patients with and without primary ciliary dyskinesia. Thorax 2003; 58: 68-72.

23. Narang I, Ersu R, Wilson NM, Bush A. Nitric oxide in chronic airway inflammation in children: diagnostic use and pathophysiological significance. Thorax 2002; 57: 586-589.

24. Machado RF, Stoller JK, Laskowski D, et al. Low levels of nitric oxide and carbon monoxide in alpha 1-antitrypsin deficiency. J Appl Physiol 2002; 93: 2038-2043.

25. Chatkin JM, Ansarin K, Silkoff PE, et al. Exhaled nitric oxide as a non-invasive assessment of chronic cough. Am J Respir Crit Care Med 1999; 159: 1810-1815.

26. Nogami H, Shoji S, Nishima S. Exhaled nitric oxide as a simple assessment of airway hyperresponsiveness in bronchial asthma and chronic cough patients. J Asthma 2003; 40: 653-659.

27. Gratziou C, Lignos M, Dassiou M, Roussos C. The influence of atopy on exhaled nitric oxide in patients with asthma and/or rhinitis. Eur Respir J 1999; 14: 897-901.

28. Busse WW, Vrtis RF, Dick EC. The role of viral infections in intrinsic asthma: activation of neutrophil inflammation. Agents Actions Suppl 1989; 28: 41-56.

29. Jatakanon A, Lim S, Kharitonov SA, Chung KF, Barnes PJ. Correlation between exhaled nitric oxide, sputum eosinophils, and methacholin responsiveness in patients with mild asthma. Thorax 1998; 53: 91-95.

30. Dupont LJ, Rochette F, Demedts MG, Verleden GM. Exhaled nitric oxide correlates with airway hyperresponsiveness in steroid-naive asthmatic patients. Am J Respir Crit Care Med 1998; 157: 894-898.

31. Steerenberg PA, Janssen NAH, de Meer G, et al. Relationship between exhaled NO, respiratory symptoms, bronchial hyperresponsiveness, and blood eosinophilia in school children. Thorax 2003; 58: 242-245.

32. Horváth I, Donnelly $L E$, Kiss A, et al. Combined use of exhaled hydrogen peroxide and nitric oxide in monitoring asthma. Am J Respir Crit Care Med 1998; 158: 1042-1046.

33. Brightling CE, Symon FA, Birring SS, Bradding P, Wardlaw AJ, Pavord ID. Comparison of airway immunopathology of eosinophilic bronchitis and asthma. Thorax 2003; 58: 528-532.

34. Meijer RJ, Postma DS, Kauffman HF, Arends LR, Koeter GH, Kerstjens HA. Accuracy of eosinophils and eosinophil cationic protein to predict steroid improvement in asthma. Clin Exp Allergy 2002; 32: 1096-1103.

35. Massaro AF, Gaston B, Kita D, Fanta C, Stamler J, Drazen JM. Expired nitric oxide levels during treatment of acute asthma. Am J Respir Crit Care Med 1995; 152: 800-803. 
36. Kharitonov $S A, O^{\prime}$ Conner BJ, Evans DJ, Barnes PJ. Allergen-induced late asthmatic reactions are associated with elevation of exhaled nitric oxide. Am J Respir Crit Care Med 1995; 151: 1894-1899.

37. Paredi P, Leckie MJ, Horváth I, Allegra L, Kharitonov SA, Barnes PJ. Changes in exhaled carbon monoxide and nitric oxide levels following allergen challenge in patients with asthma. Eur Respir J 1999; 13: 48-53.

38. Simpson A, Custovic A, Pipis S, Adisesh A, Faragher B, Woodcock A. Exhaled nitric oxide, sensitization, and exposure to allergens in patients with asthma who are not taking inhaled steroids. Am J Respir Crit Care Med 1999; 160: 45-49.

39. Baraldi E, Carra S, Dario $C$, et al. Effect of natural grass pollen exposure on exhaled nitric oxide in asthmatic children. Am J Respir Crit Care Med 1999; 159: 262-266.

40. Yates DH, Kharitonov SA, Barnes PJ. Effect of short-and long-acting inhaled $\beta_{2}$-agonist on exhaled nitric oxide in asthmatic patients. Eur Respir J 1997; 10: 1483-1488.

41. Deykin A, Belostotsky 0, Hong C, Massaro AF, Lilly CM, Israle E. Exhaled nitric oxide following leukotriene E4 and methacholine inhalation in patients with asthma. Am J Respir Crit Care Med 2000; 162: 1685-1689.

42. de Gouw HW, Hendriks J, Woltman AM, Twiss IM, Sterk PJ. Exhaled nitric oxide (NO) is reduced shortly after bronchoconstriction to direct and indirect stimuli in asthma. Am J Respir Crit Care Med 1998; 158: 315-319.

43. Baraldi E, Azzolin NM, Zanconato S, Dario C, Zaccbello F. Corticosteroids decrease nitric oxide in children with acute asthma. J Pediatr 1997; 131: 381-385.

44. Yates DH, Kharitonov SA, Robbins RA, Thomas PS, Barnes PJ. Effect of nitric oxide synthase inhibitor and a glucocorticosteroid on exhaled nitric oxide. Am J Respir Crit Care Med 1995; 52: 892-896.

45. Kharitonov SA, Yates DH, Chung KF, Barnes PJ. Changes in the dose of inhaled steroid affect exhaled nitric oxide levels in asthmatic patients. Eur Respir J 1996; 9: 196-201.

46. Jatakanon A, Kharitonov SA, Lim S, Chung KF, Barnes PJ. Effect of differing doses of budenoside on markers of airway inflammation in patients with mild asthma. Thorax 1999; 54: 108-114.

47. Little SA, Chalmers GW, MacLeod KJ, McSharry C, Thomson NC. Non-invasive markers of airway inflammation as predictors of oral responsiveness in asthma. Thorax 2000; 55: 232-234.

48. Nelson BV, Sears S, Woods J, et al. Expired nitric oxide as a marker for childhood asthma. J Pediatr 1997; 130: 423-427.

49. Bisgaard H, Loland L, Anhol J. NO in exhaled air of asthmatic children is reduced by the leukotriene receptor antagonist montelukast. Am J Respir Crit Care Med 1999; 160: 1227-1231.

50. Tamaoki J, Kondo M, Sakai N, et al. Leukotriene antagonist prevents exacerbation of asthma during reduction of highdose inhaled corticosteroid. Am J Respir Crit Care Med 1997; 155: 1235-1240.

51. Lim S, Tomita K, Carramori G, et al. Low-dose theophylline reduces eosinophilic inflammation but not exhaled nitric oxide in mild asthma. Am J Respir Crit Care Med 2001; 164: 273-276.

52. Jatakanon A, Lim S, Barnes PJ. Changes in sputum eosinophils predict loss of asthma control. Am J Respir Crit Care Med 2000; 161: 64-72.

53. Stirling RG, Kharitonov $S A$, Campbell D, et al. Increase in exhaled nitric oxide levels in patients with difficult asthma and correlation with symptoms and disease severity despite treatment with oral and inhaled and corticosteroids. Thorax 1998; 53: 1030-1034.

54. Jones SL, Kittelson J, Cowan J0, et al. The predictive value of exhaled nitric oxide measurements in assessing changes in asthma control. Am J Respir Crit Care Med 2001; 164: 738-743.

55. Sippel JM, Holden WE, Tilles $S A$, et al. Exhaled nitric oxide levels correlate with measures of disease control in asthma. J Allergy Clin Immunol 2000; 106: 645-650.

56. Pijnenburg MW, Hofhuis W, Hop WC, De Jongste JC. Exhaled nitric oxide predicts asthma relapse in children with clinical asthma remission. Thorax 2005; (in press).

57. Jones SL, Kittelson J, Cowan JO, Flannery EM, Hancox RJ, McLachlan CR. The predictive value of exhaled nitric oxide measurements in assessing changes in asthma control. Am J Respir Crit Care Med 2001; 164: 738-743.

58. Leuppi JD, Salome CM, Jenkins CR, et al. Predictive markers of asthma exacerbation during stepwise dose reduction of inhaled corticosteroids. Am J Respir Crit Care Med 2001; 163: 406-412.

59. Horváth I, Donnelly LE, Kiss A, Balint B, Kharitonov SA, Barnes PJ. Exhaled nitric oxide and hydrogen peroxide concentrations in asthmatic smokers. Respiration 2004; 71: 463-468.

60. Horvath I. Exhaled breath condensate in disease monitoring. Clin Pulm Med 2003; 10: 195-200.

\section{Suggested answers}

1. Yes, the measurement of exhaled NO.

2. To exhale with a constant flow (because exhaled NO concentration is expiratory-flow dependent) and against resistance (to close the soft palate to exclude NO produced in nasal parts).

3. In untreated patients, it is suggestive of ongoing eosinophilic inflammation that probably will respond to treatment with steroids. One should consider asthma as the likely diagnosis and make appropriate steps for diagnosis. If this high NO value is seen in steroid-treated patient, it reflects uncontrolled airway inflammation, and potential reasons should be investigated (lack of compliance, insufficient steroid dose, allergen exposure or, very rarely, steroid resistance).

4. It is a cooled exhaled breath sample that contains many different mediators, including adenosine, protons, 8-isoprostane, hydrogen peroxide, different interleukins, many of them being proposed biomarkers for different aspects of airway diseases.

\section{Useful web links}

Recommendations for exhaled NO measurement.

www. thoracic.org/statements

Access to material presented on the ERS School Course entitled "Monitoring of airway diseases". www.ersnet.org 